\title{
Global Warming and the Political Ecology of Health: Emerging Crisis and Systemic Solutions
}

\author{
Hans Baer and Merrill Singer. 2008. Left Coast Press, Inc., Walnut Creek, CA. Pp. 238. \$32.95 (paperback). ISBN
}

978-1-59874-354-8.

Reviewed by Kate Smith

Reviewer Address: 421 W North St, Fayatteville, AR 72701

Received: March 12, 2012

Published: June 14, 2012
Volume 3:31-32

(C) 2012 Society of Ethnobiology
If one is at all interested in the influence that the environment has on society and vice versa, this book by Hans Baer and Merrill Singer, will be a fascinating read. Baer, a senior lecturer in the Development Studies Program and the Center of Health and Society at the University of Melbourne, and Singer, a Senior Research Scientist at the University of Connecticut's Center for Health, Intervention, and Prevention, make a compelling argument for the affects of global warming and climate change as the single greatest threat to human health today.

Walking through the book in order, the first chapter provides a solid defense of climate change's validity as a global phenomenon. Those readers keeping abreast on the discussion of global climate change will notice that Singer and Baer have chosen citations from publications prior to 2008, rendering it quite dated. Reading it today, several years after publication, an argument may be made for the inclusion of more recent findings; however, the citations included by the authors are no less relevant, merely less than current. That said, this section does not limit itself to describing the reality of global warming but also begins to read as a diatribe against the evils of capitalism; a feeling that is confirmed later in the book in chapters 7 and 8 by the authors' adamant exhortation that no form of capitalism can mitigate global warming and that ecosocialism is the best solution to fix what capitalism has broken.

Chapter 2 addresses the destruction of traditional foodways and subsistence patterns by changing climate, such as those of the Inuit in the Northern realms, an area where changes in seasonal weather patterns and surface temperatures has already had a measurable effect on human lifeways (Leduc 2010), but it is in chapters 3 through 6 that the authors' contribution to the conversation about how human health will be affected by climate change becomes evident. Those hundred odd pages comprise a fascinating discussion and synthesis of the myriad ways that climate change can and has affected human health, ranging from structural power and health disparities to melting glaciers releasing viable pathogens.

A large portion of this section focuses on the structural power disparities that, when coupled with the associated ills of climate change, cause even greater health issues in the marginalized populations. Baer and Singer defend that malnutrition, poor water quality, expanding disease ranges, water borne illnesses, and even asthma affect the structurally impoverished the most and that "climate change is making a bad situation even worse" (p. 76). Examples cited include the expansion of disease vector ranges, the desertification and changing rainfall affecting food availability and water quality in already impoverished areas, to increased rates of asthma caused by the syndemism of increased pollen counts amplified by the bronchoaggravating effects of diesel particles binding to the pollen itself, and the spread of water borne diseases. It is interesting to note that Baer and Singer specifically highlighted the epidemic potential of cholera due to increased flooding and natural disasters, but that it had not occurred to them that cholera could be spread in the site of a natural disaster by aid workers coming to provide relief (e.g. Haiti post-quake). It is interesting to remark that neither author actually mentioned the term "structural power" or cited the work of Eric Wolf or that of Paul Farmer (beyond a quick quotation of Farmer's in the initial chapters), despite the influence both figures have had in the forums of both political ecology and public health. Despite this lack, the case studies mentioned and the support they provide for their hypotheses are extremely well thought out and 
make for an excellent and thought-provoking introduction to the political ecology of health.

\section{References Cited}

Leduc, T. B. 2010. Climate, Culture, Change: Inuit and Western Dialogues with a Warming North. University of Ottawa Press. 